\title{
OS AUTOS CRIMINAIS E AS POSSIBILIDADES DE PESQUISA EM HISTÓRIA REGIONAL
}

Enezila de Lima'

Resumo: Neste artigo destacamos a importância dos Centros de Documentação para o estudo da história regional, bem como a utilização de processos judiciais, em especial os autos criminais, como fonte documental para o estudo de diferentes temas na área de pesquisa dos movimentos sociais, a partir de nossa experiência na organização do acervo documental do Fórum da Comarca de Londrina, 1934-1970, sob guarda do Centro de Documentação e Pesquisa Histórica do Departamento de História da UEL.

Unitermos: história regional; Centros de Documentação; fontes judiciais; autos criminais; movimentos sociais.

Na conclusão de seu artigo Região e História: questão de método, Rosa Maria Godoy Silveira (1990:17) afirma que um dos efeitos da revisão teórico-metodológica da questão regional, entendida enquanto espaço socialmente produzido, é a estruturação de Centros de Documentação e Pesquisa Histórica Regional que, ao possibilitar elementos para a caracterização de sua área de abrangência, forneceria indicações dos temas e problemas a serem documentados e pesquisados.

A existência de Centros de documentação na UEL e na UEM, a constituição de linhas de pesquisa nas duas instituições e a implantação do mestrado em História Social são indicadores da importância que assumirá a pesquisa de enfoque regional.

\footnotetext{
${ }^{1}$ Docente do Departamento de História da Universidade Estadual de Londrina e do Programa Associado de Pós-Graduação em História UEM/UEL.
}

Hist. Ensino, Londrina, v. 6, p. 121-130, out. 2000 
É possível afirmar que se até o momento a pesquisa regional ocupava um espaço ainda pouco expressivo nas nossas atividades de pesquisa, ela assume importância vital para a manutenção do mestrado em fase de implantação. Pensando nesse compromisso, nos trabalhos já orientados e voltados para o estudo regional, acredito ser de importância fundamental trazer à reflexão as possibilidades de pesquisa na área de movimentos sociais.

Entendendo que as linhas de pesquisa não são estanques, não apenas de tangenciam, mas se interpenetram, muitas das possibilidades aqui levantadas podem dizer respeito a outras linhas, sem que, com isso, se perca a dimensão de tratamento específico e das preocupações que norteiam as diferentes propostas.

Partindo de nossa realidade, Norte do Paraná - espaço que no passado pertenceu à Província de Guairá dirigida por jesuítas espanhóis -, ocupada a partir dos anos 30 deste século por uma empresa privada estrangeira que orientou sua ocupação, verifica-se a existência de uma vasto campo de pesquisa a ser explorado.

O povoamento do Norte do Paraná foi extremamente rápido, tanto assim, que nos anos 60 essa região representava $57 \%$ do total da população do Estado. Essa rapidez de ocupação decorreu, em parte, da vasta propaganda realizada pela Companhia de Terras Norte do Paraná (CTNP), exaltando as qualidades das terras, a importância da propriedade e as facilidade de pagamento, mas também do momento histórico vivido pois, como bem salienta Verena Stoclke, essa foi a melhor época para atuação das companhias colonizadoras. ${ }^{2}$

A propaganda da CTNP reproduzia as imagens que contemplavam os desejos e as fantasias de homens e mulheres

\footnotetext{
2 STOLCKE, Verena. Cafeicultura: homens, mulheres e capital (1850-1980) Trad. Denise Bottmann e João R. Martins Filho. São Paulo: Brasiliense, 1986, pp. 86-90.
} 
portadores dos valores de uma sociedade ainda nitidamente agrária, onde a propriedade da terra ocupava um espaço privilegiado.

Com essa vasta propaganda, para cá vieram, além de compradores de terras e suas famílias, aventureiros de vários matizes. Nesse primeiro momento, trabalho e aventura entrecruzavam-se na construção da cidade, numa aparência de igualdade - oportunidades iguais para todos - que homogeneizava os atores sociais envolvidos no processo.

Em Londrina, na zona urbana, ao lado do comércio, das pequenas indústrias e das oficinas de consertos, surgiram hotéis, pensões, confeitarias, bares, mas também as casas de prostituição e de jogo.

No acervo Autos Criminais do Fórum da Comarca de Londrina, do Centro de Documentação e Pesquisa Histórica do Departamento de História da UEL, inúmeros são os inquéritos policiais e processos crimes que se referem às casas de prostituição, a ladrões vindos de outras localidades, a fugitivos de presídios, ao estelionato, a roubos de casas comerciais e postos de gasolina, a venda de terras, carros, animais e madeira inexistentes - os famosos golpes milionários. Também já era hábito elementos da própria polícia promoverem ou facilitarem a fuga de presos sob suspeita ou de sentenciados

A presença de parte desse acervo no Centro de Documentação e Pesquisa História (CDPH), está ligada à renovação teórico-metodológica que, desde os anos sessenta, vem ocorrendo nos estudos históricos, com a valorização de temporalidades, temas e sujeitos até então pouco atraentes ou esquecidos pelos historiadores: a natureza do poder; as lideranças carismáticas e a autoridade; o trabalho, os trabalhadores e o lazer; a mulher, a infância e a velhice; os padrões de educação e de saúde - morbidade e mortalidade; a violência, a marginalidade e a criminalidade, entre outros. ${ }^{3}$ Essa

${ }^{3}$ STONE, L. O renascimento da narrativa: reflexões sobre uma nova velha história. Past and Present, n. 85, pp. 3-24, nov. 79 [Trad. Dulce Amarante da Silva Ramos].

Hist. Ensino, Londrina, v. 6, p. 121-130, out. 2000 
renovação ampliou e redefiniu o conceito de fonte histórica e de documento enquanto prova, testemunho, evidência.

Segundo Michel de Certeau ${ }^{4}$, na atualidade, o historiador "avança na direção das fronteiras das grandes regiões exploradas", desviando-se "em direção à bruxaria, à loucura, à festa, à literatura popular, ao mundo esquecido do camponês", e a "todas até então zonas silenciosas. Trabalha nas margens [e], sob esse ponto de vista, torna-se um andarilho".

Andarilho, porque a documentação referente a esses sujeitos históricos, via de regra, não está ordenada em museus, bibliotecas e arquivos, mas deve ser buscada nos diferentes desvãos de suas existências. Os autos criminais são uma documentação que permite buscar nos desvãos das ações humanas as suas representações, desejos e frustrações.

A rapidez da ocupação, sua inserção na economia nacional graças à produção cafeeira, bem como os problemas dela decorrentes, aqui reproduziam, talvez não com a mesma dimensão, os mesmos problemas que, a partir de meados dos anos sessenta, marcaram a sociedade brasileira com a "modernização conservadora", isto é, a substituição de culturas permanentes por culturas temporárias próprias à mecanização agrícola, uso de insumos, etc., no intuito de, por um lado, contribuir para a acumulação de capital para o parque industrial em implantação e, por outro, formar um exército de reserva para essa mesma indústria. Ou seja, em apenas trinta anos, o Norte do Paraná, que representava $57 \%$ da população do Estado, já presenciava a concentração da propriedade, o êxodo rural, o endividamento de pequenos proprietários e a migração para novas fronteiras que se abriam no Norte do País.

O êxodo rural acarretou problemas urbanos, notadamente de infra-estrutura e saneamento básico. Os problemas já

${ }^{4}$ CERTEAU, M. A operação histórica. In LE GOFF, J. \& NORA, P. História: novos problemas. Trad. Theo Santiago. 2. ed. Rio de Janeiro: Francisco Alves, 1979 , p. 35. 
existentes - falta de moradias, transportes coletivos e limpeza pública deficitários -, agravaram-se pois, o crescimento não de fez acompanhar da expansão desses serviços. Por sua vez, o setor de moradias foi e é agravado pela ação do poder público que, pressionado pelos movimentos populares, vem liberando áreas sempre mais periféricas e impróprias para tal fim; a essa ação junta-se a de agentes imobiliários ávidos pelo lucro, com loteamentos clandestinos e sem infra-estrutura urbana, contribuindo para a sua proliferação em áreas de vertentes íngremes impróprias à instalações urbanas e responsáveis por deslizamentos e enchentes, até bem pouco tempo, inexistentes na cidade.

Ao lado desse adensamento urbano, crescem as favelas, as ocupações de fundo dos vales, a mendicância, os menores infratores que vagueiam pelas ruas, as diferentes modalidades de assaltos acompanhados de homicídios; o tráfico de drogas, a prostituição de menores de ambos os sexos; enfim, a violência, com suas várias faces, presente no cotidiano da cidade.

Sem entrar em detalhes dessa ocupação que já foi objeto de vários e diferentes trabalhos, percebe-se a riqueza de possibilidades de pesquisa.

Os autos criminais se constituem numa documentação que permite recuperar esses diferentes aspectos da vida social da cidade. Constituído por dois eventos - o delito e o processo que se estabelece para apurar os atos e os fatos que envolvem as pessoas -, o auto criminal é um documento que pode ser utilizado para a análise e compreensão de vários aspectos dessa época: a conduta das pessoas, seus valores, suas representações; o quotidiano da cidade, a estrutura familiar, as relações de vizinhança, as diferentes formas de violência; as relações entre as instituições políticas, os padrões sociais e o sistema de valores então existentes; os conflitos e as manifestações das pessoas, as diferentes formas de transgressão às normas sociais; os delitos mais comuns e que se repetem; a organização do poder judiciário e da força policial, 
bem como o desempenho desses poderes em suas funções, entre outras tantas questões.

A exploração da riqueza dos autos, enquanto representativos de uma sociedade, vai depender muito do pesquisador, uma vez que os dados não estão prontos. Há que se ler nas entrelinhas das denúncias e das queixas, dos depoimentos, das versões sobre os fatos, das inverdades, das ambigüidades, enfim do complexo material que se tem às mãos.

O fato de ser uma documentação produzida por um órgão encarregado do estabelecimento da ordem, torna os autos portadores dos valores da sociedade que os produziu. Porém, para que o mesmo se transforme em documento há que se proceder à sua crítica - buscar as condições de sua produção histórica, ou seja, a sua intencionalidade inconsciente. Contudo, se, na sua forma tradicional de trabalho, o historiador buscava, por meio da crítica interna, comprovar a autenticidade do documento, para tomá-lo como testemunho, prova ou evidência, hoje, há que se analisar o documento enquanto documento, i. é., enquanto representativo da sociedade e da época que o produziram, como bem assinala Le Goff (1984: 102):

"O documento não é qualquer coisa que fica por conta do passado, é produto de uma sociedade que o fabricou segundo as relações de forças que aí detinham o poder.(...) $\mathrm{O}$ documento não é inócuo. É antes de mais nada o resultado de uma montagem consciente ou inconsciente, da história, da época, da sociedade que o produziram, mas também de épocas sucessivas durante as quais continuou a viver, talvez esquecido, e (...) manipulado ainda que pelo silêncio".

$\mathrm{O}$ autor esclarece que os documentos produzidos espontaneamente e à dispo-sição do historiador, enquanto um legado do passado, são marcados por uma determinada cultura política, logo, não são inocentes ou neutros, pois neles se manifestam os interesses, os conflitos e as visões de mundo dos diferentes agentes sociais da época. Para o autor, essa "marca do passado" só é significativa à medida em que responde 
aos questionamentos do presente, pois é o presente que dá vida ao passado. É o pesquisador que, ao selecionar um documento como representativo de uma época e interrogá-lo, a partir de suas próprias motivações, numa operação que nada tem de neutralidade, que traz para o presente os sujeitos históricos do passado. Portanto, o historiador, ao selecionar um documento

(...) extraindo-o do conjunto de dados do passado, preferindoo a outros, atribuindo-Ihe um valor de testemunho que, pelo menos em parte, depende da sua própria posição na sociedade da sua época e da sua organização mental, insere-se numa situação que é ainda menos "neutra" do que a sua intervenção." (LE GOFF, 1984: 547)

A utilização dos autos, como fonte de pesquisa, não é de aceitação unânime entre especialistas porque, argumentam alguns, essa documentação não corresponde à exata realidade do que se passou. Porém, essa não deve ser uma preocupação do historiador porque, com a revolução documental, a pretensão em alcançar uma representação pura e verdadeira do passado cedeu lugar uma certa à subjetividade, inerente ao trabalho do historiador, no qual também se manifestam seus interesses, seus conflitos e sua visão de mundo. Ou seja, toda a produção historiográfica traz a marca de seu tempo, à medida em que o pesquisador convive com versões conflitantes e inversões próprias de qualquer realidade histórica. Há que se considerar, também, que o "pêndulo das interpretações históricas" sempre oscila revelando novos fatos e novas leituras sobre velhos fatos, visões parciais ou mesmo complementares, eliminando visões distorcidas ou desacreditadas. Uma nova leitura de um processo criminal, ou de qualquer outra fonte selecionada pelo pesquisador, pode lançar dúvidas sobre antigas certezas e estabelecer conexões insuspeitas. Assim as interpretações e diferentes versões são

Hist. Ensino, Londrina, v. 6, p. 121-130, out. 2000 
"(...) inacabadas no sentido de que o futuro sempre utiliza seu passado de novas maneiras. Mas este argumento não afeta em absoluto a questão de que uma interpretação é uma tentativa de oferecer uma explicação objetiva de um passado também objetivo..." (GAY, 1990:191)

Os autos, bem como boa parte dos documentos, não são fontes objetivas, em especial porque são produzidos por uma instituição repressora, que busca estabelecer um controle social sempre mais sutil e minucioso sobre o corpo social. Porém, eles permitem captar as inúmeras sutilezas ideológicas que permeiam as estruturas sociais, notadamente as do capitalismo maduro. (GINSBURG, 1991: 177)

Sidney Chalhoub (1986: 23), que se utilizou de autos criminais para recuperar a memória dos trabalhadores da cidade do Rio de Janeiro na transição do trabalho escravo para o trabalho livre, afirma que a leitura dos processos criminais não deve levar-nos à perspectiva 'inocente' de ir em busca do que realmente se passou, mas às 'coisas' que, de forma sistemática, se repetem. Cada auto é uma história e cada história é uma encruzilhada de muitas lutas - as lutas de classes das sociedades.

Apesar de se constituírem, segundo Carlo Ginsburg (1991:177), numa documentação "exígua, dispersa e renitente", os autos permitem resgatar as representações de um cotidiano saturado de hostilidades e violência e identificar o espaço entre o formal e o real - entrecruzando-se com a história do processo de urbanização e ordenação de uma cidade como Londrina, por exemplo. Há, sem sombra de dúvida, as armadilhas implícitas nas fontes: o domínio da lei; as versões contraditórias impossíveis de serem comprovadas; as provas, verídicas, inverídicas ou mesmo forjadas; a vingança, a traição, a paixão, o ódio, presentes nos depoimentos e a clivagem do tempo quando do interrogatório na delegacia e, posteriormente, no poder judiciário. Atentos a esses embustes, a recuperação ou reconstituição daquilo que for possível, é a etapa na qual a 
interação do pesquisador com as fontes, sua criatividade e erudição irão se configurar como elementos chave para o conhecimento e a construção desse passado presentificado nos autos.

Ao analisar o paradigma indiciário, em especial as impressões digitais, que tiram os indivíduos do anonimato conferindo-Ihes identidade e individualidade, Ginsburg alerta para a existência de uma realidade opaca, para as quais existem zonas privilegiadas, i. é., sinais e pistas que permitem decifrar a opacidade da trama. Os autos são essas zonas privilegiadas, páginas nas quais as pessoas deixam registrados seus movimentos e seus pensamentos secretos - sonhos, medos, angústias, esperanças, frustrações... As entrelinhas de um auto explicitam as diferentes emoções humanas - paixões, desejos, instintos, desajustes, impulsos, agressividades - que caracterizam um crime ou delito, sempre julgados a partir de estratégias da acusação e da defesa, e de regras estabelecidas pelo poder judiciário.

Com isso, o autor nos alerta para as armadilhas e as reticências presentes nessa documentação, o que não invalida sua utilização como fonte de pesquisa na linha de movimentos sociais.

\section{REFERÊNCIA BIBLIOGRÁFICA:}

CERTEAU, M. A operação histórica. In LE GOFF, J. \& NORA, P. História: novos problemas. Trad. Theo Santiago. 2. ed. Rio de Janeiro: Francisco Alves, 1979, p. 35.

CHALHOUB, S. Trabalho, lar e botequim: o cotidiano dos trabalhadores no Rio de Janeiro da Belle Époque. São Paulo: Brasiliense, 1986.

FAUSTO, Bóris.. Crime e cotidiano: a criminalidade em São Paulo (1880-1924). São Paulo: Brasiliense, 1984, p. 21.

GAY, P. O estilo na história: Gibbon, Ranke, Macaulay, Buckhardt. Trad. Denise Bottmann. São Paulo: Companhia das Letras, 1990. 
GINSBURG, C. Mitos, emblemas, sinais: morfologia e história. Trad. Feredico Carotti. São Paulo: Companhia das Letras, 1991.

LE GOFF, J. História e memória. In Memória-História. Trad. Bernardo Leitão et al. Portugal [Porto]: Imprensa Nacional: Casa da Moeda, 1984.

SILVEIRA, Rosa Maria Godoy. Região e História: questão de método. In SILVA, Marcos (org.). República em migalhas: História Regional e local. São Paulo: Marco Zero: Brasília MCT/CNPq, 1990

STOLCKE, Verena. Cafeicultura: homens, mulheres e capital (1850-1950). Trad. Denise Bottmann e João R. Martins Filho. São Paul: Brasiliense, 1986.

STONE, L. O renascimento da narrativa: reflexões sobre uma nova velha história. Past and Present, n. 85, pp. 3-24, nov. 79 [Trad. Dulce Amarante da Silva Ramos].

Abstract: In this article we highlight the importance of the Documentation Centers for the study of the regional history, as well as the use of lawsuits, especially the criminal records, as documental source for the study of different themes in the research area of the social movements, starting from our experience in the organization of the documental collection of the Court of the City of Londrina, 19341970, under guard of the Center of Documentation and Researches Historical of the History Department of UEL.

Keywords: regional history; Documentation Centers; judicial sources; criminal records; social movements. 